\title{
Porównanie dokładności dwóch metod pomiaru emisji lotnych - według normy EN 15446 oraz z zastosowaniem urządzenia Hi Flow Sampler - wyniki projektu GERG (The European Gas Research Group)
}

\begin{abstract}
Przedstawiono wyniki projektu zrealizowanego przez GAZ-SYSTEM wspólnie z 4 innymi europejskimi firmami gazowniczymi. Pomiary emisji przeprowadzane były przez dwóch różnych wykonawców na stanowisku badawczym, które zostało wybudowane przez GdF Suez (Crigen). Celem projektu było wykonanie pomiarów emisji gazu za pomocą dwóch różnych metod, a następnie porównanie otrzymanych wyników i ocena ich miarodajności, a także ocena przydatności tych metod do pomiarów emisji z sieci przesyłowej.
\end{abstract}

Słowa kluczowe: lotna emisja gazu, metody pomiaru, dokładność pomiaru.

\section{Comparison of the accuracy of two methods of methane fugitive emissions} measurements - one according to EN 15446 standard and the other using the Hi Flow Sampler device - GERG (The European Gas Research Group) project results

\begin{abstract}
In the paper are presented results of a project realized by GAZ-SYSTEM, together with 4 other European gas companies. Emissions were measured by two different contractors on a test bench built by GdF Suez (Crigen). The aim of the project, was to perform emission measurements, with two different methods and then to compare the results and assess their reliability, for emissions measurements in transmission networks.
\end{abstract}

Key words: fugitive gas emission, measurement methods, measurement accuracy.

\section{Wprowadzenie}

Projekt „Comparison of the accuracy of two methods of methane fugitive emissions measurements - one according to EN 15446 standard and other using Air Flow Method and a Hi Flow Sampler device" został zrealizowany przez firmy stowarzyszone w GERG jako kontynuacja projektu „Inventory of Natural Gas Emissions Measurement Method" z 2010 roku, którego wynikiem było wskazanie metody z opływem powietrza jako najbardziej przydatnej do pomiaru lotnych emisji gazu ziemnego [2].

Obecnie do oszacowania wielkości emisji lotnych stosowana jest $w$ Europie norma EN 15446:2008 Fugitive and dif- fuse emissions of common concern to industry sectors - Measurement of fugitive emission of vapours generating from equipment and piping loss, która podaje wymagania odnośnie do lokalizacji uchodzeń gazu oraz do oszacowania emisji (w jednostkach masy) z obiektów przemysłowych w określonym przedziale czasu, na podstawie pomiaru stężenia gazu w pobliżu nieszczelnego elementu i zastosowania odpowiedniej korelacji. W normie wymienione są dwie różne korelacje: US EPA SOCMI i US EPA Petroleum Industry, ale dopuszcza się również te, które są zdefiniowane przez użytkownika. Nie ma jednak korelacji dla systemu przesyłu 
gazu, a wśród członków GERG pojawiają się opinie, że oszacowanie emisji za pomocą tej normy daje wyniki niewłaściwe (zawyżone).

GAZ-SYSTEM, ENAGAS, National Grid, SNAM i GdF Suez (obecnie ENGIE) postanowiły, że celowe jest porównanie dwóch różnych metod pomiaru emisji - metody według [4] oraz metody z użyciem opływu powietrzem. Urządzeniem, które wykorzystuje tę metodę, jest Hi Flow Sampler, stosowany od kilku lat do pomiaru emisji z różnych obiektów systemu przesyłowego GAZ-SYSTEM, ale także przez inne firmy gazownicze w Europie.

Celem projektu było porównanie wyników pomiarów wykonanych na stanowisku laboratoryjnym w Paryżu dwiema różnymi metodami. Postanowiono ponadto, że pomiary zostaną przeprowadzone przez dwóch różnych wykonawców, mających doświadczenie w stosowaniu obu wymienionych wyżej metod, co - jak oczekiwano - miało zwiększyć wiarygodność uzyskanych wyników.

\section{Stanowisko badawcze}

Stanowisko badawcze zostało wybudowane w Paryżu przez GdF Suez (Crigen). Składało się z dwóch części: w jednej znajdowały się wszystkie badane elementy o sztucznie wytworzonych nieszczelnościach, do których dostarczany był metan poprzez układ rurek doprowadzających i zaworów, a w drugiej butle z metanem pod ciśnieniem oraz układ generowania przepływu o odpowiedniej wielkości (mierzony przepływomierzem masowym) przy odpowiednim ciśnieniu.

Zakres wielkości emisji lotnych związków organicznych, przy których norma EN 15446 może być stosowana, nie jest podany, ale $\mathrm{z}$ analizy znajdujących się w niej korelacji należy przyjąć, że może być wykorzystywana do małych i średnich emisji. W przypadku korelacji SOCMI (Synthetic Organic Chemical Manufacturing Industry) największe emisje są rzędu 14,47 1/min, natomiast w przypadku korelacji EPA Petroleum Industry największa wartość emisji wynosi około 3,25 1/min. Urządzenie Hi Flow Sampler ma według [1] zakres pomiarowy od $0,09 \mathrm{~m}^{3} / \mathrm{h}$ (co odpowiada $1,42 \mathrm{l} / \mathrm{min}$ ) do $13,5 \mathrm{~m}^{3} / \mathrm{h}$ (co odpowiada $226 \mathrm{l} / \mathrm{min}$ ).

Założono, że stanowisko pomiarowe powinno zapewniać strumień objętości metanu o wartości $0,5 \mathrm{~m}^{3} / \mathrm{h}$ przy maksymalnym ciśnieniu 60 bar. Strumień objętości z nieszczelności będzie miał zakres od około 1,67 1/min do 8,33 1/min, tak więc porównanie obu metod okaże się możliwe.

Stanowisko wyposażono w następujące elementy ze specjalnie wytworzonymi nieszczelnościami:

- otwarta rurka $6 \mathrm{~mm}$ - jeśli przepływa przez nią gaz pod ciśnieniem, przepływy są bardzo duże, stwierdzono więc konieczność kontrolowania wielkości uchodzenia za pomocą zaworu,
- połączenie gwintowane $6 \mathrm{~mm}$ : nieszczelność została wytworzona poprzez uszkodzenie gwintu,

- kołnierz DN 100 na szpulce i kołnierz DN 150 na zwężce: nieszczelności zostały wytworzone poprzez uszkodzenie metalowych uszczelek oraz nieprawidłowe włożenie śrub mocujących kołnierze,

- zawory DN 100 i DN 150: uszkodzono uszczelkę i grafitowe uszczelnienie.

Po wytworzeniu nieszczelności sprawdzono poszczególne elementy na stanowisku w Alfortville, w południowej części Paryża, w zakresie ciśnień od 4 bar do 30 bar. Nieszczelności wymagały kilkukrotnych modyfikacji w celu osiągnięcia uchodzenia założonego strumienia objętości gazu. Po sprawdzeniu wszystkie elementy przewiezione zostały do siedziby Crigen w Saint-Denis (Paryż), gdzie zmontowano stanowisko docelowe (rysunek 1).

Wykonawcy przeprowadzili łącznie 120 pomiarów emisji, po 60 każdą z metod, co przedstawiono w tablicy 1 .

Dla założonych kombinacji przepływu i ciśnienia zastosowano następującą procedurę pomiarową:

1) ustawienie wielkości uchodzenia na danym elemencie przez Crigen,

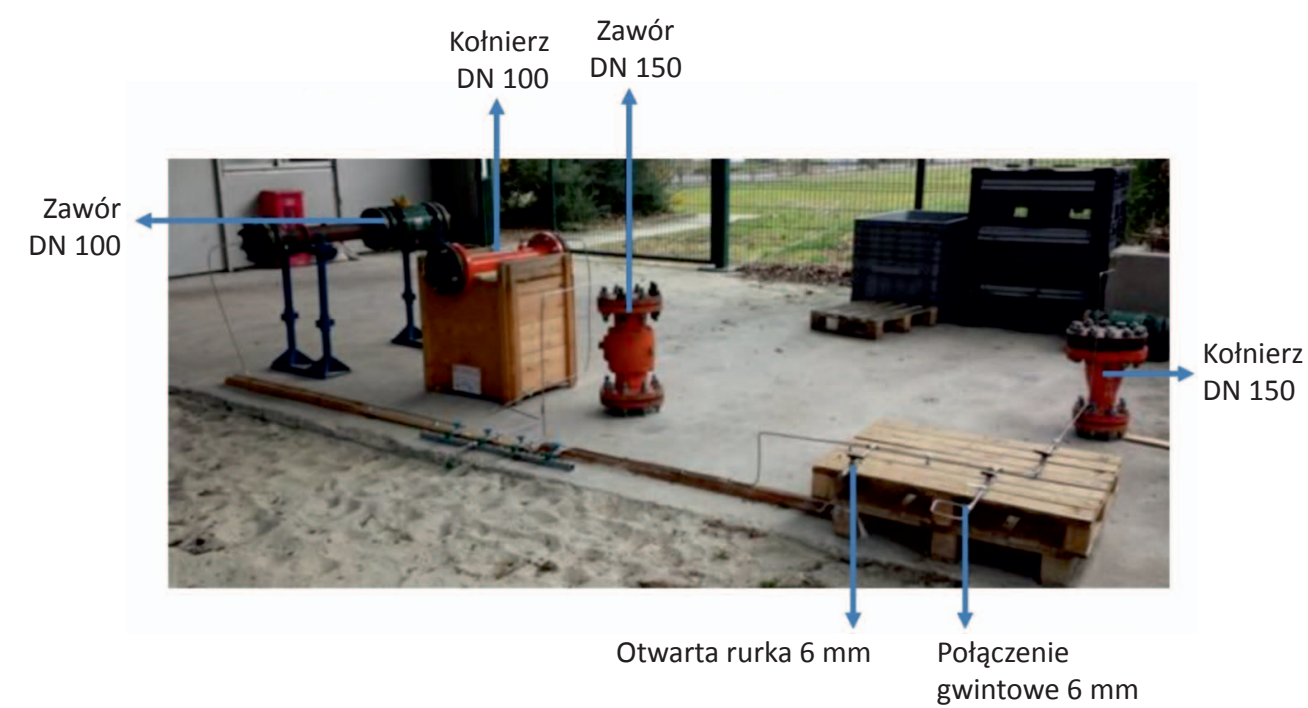

Rys. 1. Widok stanowiska z rozszczelnionymi elementami 
2) pomiar przez Crigen zadanego uchodzenia przy użyciu detektora RMLD $(R e-$ mote Methane Leak Detector), który mierzy stężenie już od 1 ppm,

3) pomiar emisji na danym elemencie zgodny z normą EN 15446 - wykonawca,

4) powtarzanie kroków $1 \div 3$ dla wskazanych warunków pomiarowych i wybranych elementów przy wykorzystaniu normy EN 15446,
Tablica 1. Liczba pomiarów wykonanych przez każdego z wykonawców

\begin{tabular}{|c|c|c|c|c|c|c|}
\cline { 2 - 7 } & \multicolumn{6}{c|}{ Nieszczelne elementy } \\
\cline { 2 - 7 } & $\begin{array}{c}\text { otwarta } \\
\text { rurka 6 mm }\end{array}$ & $\begin{array}{c}\text { połączenie } \\
\text { gwintowe }\end{array}$ & $\begin{array}{c}\text { połączenie } \\
\text { kołnierzowe } \\
\text { DN 100 }\end{array}$ & $\begin{array}{c}\text { połączenie } \\
\text { kołnierzowe } \\
\text { DN 150 }\end{array}$ & zawór 1 & zawór 2 \\
\hline Według EN 15546 & 9 & 15 & 9 & 9 & 9 & 9 \\
\hline Hi Flow Sampler & 9 & 15 & 9 & 9 & 9 & 9 \\
\hline
\end{tabular}

5) powtarzanie kroków $1 \div 3$ dla wskazanych warunków pomiarowych na wszystkich wybranych elementach przy zastosowaniu urządzenia Hi Flow Sampler.

\section{Opis metod pomiaru}

\section{Metoda opisana w [4]}

Metoda bazuje na dokumencie Agencji Ochrony Środowiska - agencji federalnej USA - EPA 21 [3]. Zgodnie z normą można oszacować emisję lotnych związków organicznych (VOC) z różnych źródeł, takich jak zawory, kołnierze, połączenia różnych innych typów, a także oszacować całkowitą emisję z obiektu przemysłowego, wykonując pomiar stężenia VOC. W normie podano wymagania dla urządzenia mierzącego stężenie, m.in. następujące:

- dolny próg detekcji powinien wynosić 10 ppm lub mniej,

- rozdzielczość urządzenia ma być w granicach $\pm 5 \%$ stężenia granicznego,

- przepływ przez urządzenie powinien wynosić pomiędzy $0,21 / \mathrm{min}$ a $1,21 / \mathrm{min}$,

- minimalny zakres pomiarowy urządzenia powinien być równy co najmniej 50000 ppm, a czas odpowiedzi $T_{90 \%}$ powinien wynosić $5 \mathrm{~s}$ lub mniej.

\section{Metoda z opływem powietrzem i z użyciem urządzenia Hi Flow Sampler}

Emisja $\mathrm{z}$ danego elementu jest mierzona przez wygenerowanie przepływu powietrza wokół badanego elementu i jednoczesny pomiar strumienia objętości mieszaniny gazu i powietrza oraz stężenia gazu w tej mieszaninie. W zakresie pomiarowym urządzenia producent deklaruje 10-proc. dokładność. Aby upewnić się, że urządzenie zbiera cały gaz uchodzący z nieszczelności, pomiary wykonuje się przy dwóch różnych wartościach strumienia objętości gazu. Zgodnie z [1]:

- pierwszy pomiar powinien być dokonany przy maksymalnej osiąganej wartości strumienia objętości,

- drugi pomiar powinien być dokonany przy strumieniu objętości wynoszącym około 70 $\div 80 \%$ pierwszego,

- jeżeli różnica nie jest większa niż 10\%, wyniki uznaje się za poprawne.

Tablica 2. Urządzenia stosowane przez obu wykonawców

\begin{tabular}{|l|l|l|}
\hline Wykonawca & \multicolumn{1}{|c|}{ Notoda } & \multicolumn{1}{|c|}{ Metoda z opływem powietrzem } \\
\hline Wykonawca A & $\begin{array}{l}\text { Toxic Vapor Analyzer (TVA) 1000 B } \\
\text { (Thermo Instruments) }\end{array}$ & $\begin{array}{l}\text { Hi Flow Sampler (Bacharach Inc.) } \\
\text { Toxic Vapor Analyzer (TVA) 1000 B } \\
\text { (Thermo Instruments) }\end{array}$ \\
\hline Wykonawca B & SIGI Ex2 (ESDERS GmbH) & Hi Flow Sampler (Bacharach Inc.) \\
\hline
\end{tabular}

\section{Wyniki pomiarów}

\section{Wyniki uzyskane według [4]}

Obie korelacje - EPA SOCMI oraz EPA Petroleum Industry zostały zastosowane do oszacowania wielkości emisji. Wartościami odniesienia były wielkości emisji wygenerowane na stanowisku badawczym i zmierzone za pomocą przepływomierza masowego. Wyniki przedstawiono na rysunku 2. Wynika z niego, że nie występuje zależność pomię- dzy rezultatami otrzymanymi przez obu wykonawców a wartościami odniesienia.

Średnie wartości błędów wyznaczono dla wyników obu wykonawców. Należy podkreślić, że wykonawcy nie znali wartości odniesienia w czasie wykonywania pomiarów, a operator stanowiska generował je w sposób przypadkowy. W tablicy 3 zestawiono wyznaczone błędy. 

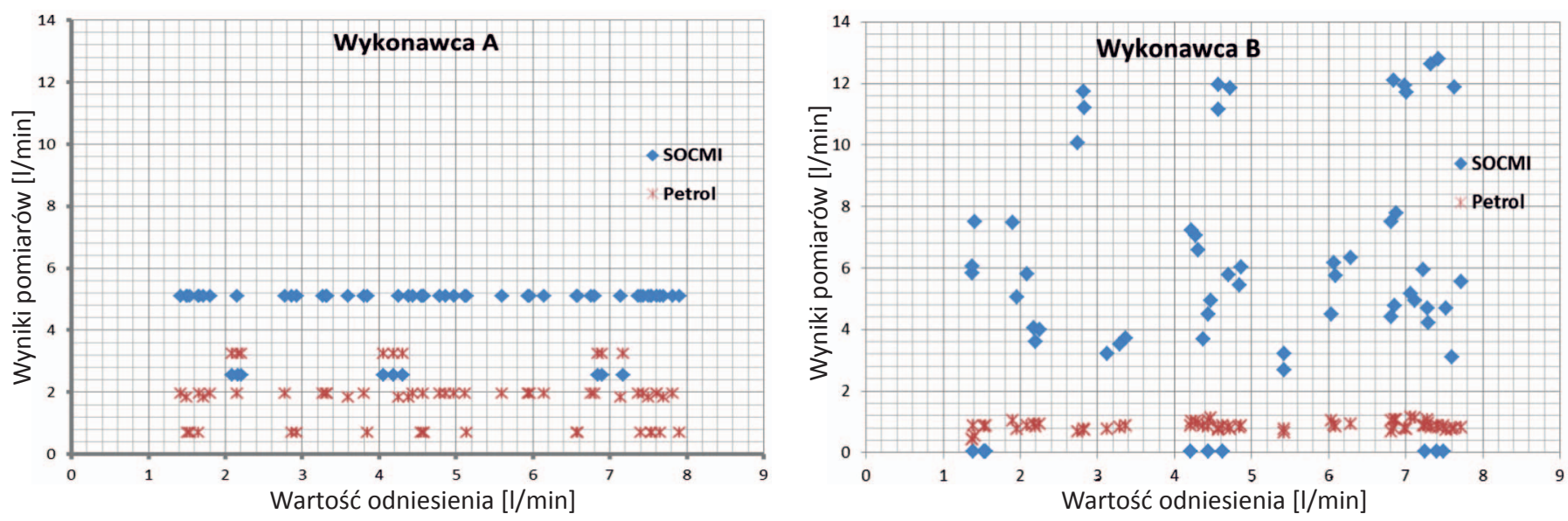

Rys. 2. Wyniki otrzymane przez wykonawców A i B w funkcji wartości odniesienia

Tablica 3. Błędy średnie wyznaczenia emisji metodą według EN 15446

\begin{tabular}{|l|c|c|c|c|}
\cline { 2 - 5 } \multicolumn{1}{c|}{} & Wykonawca A & Wykonawca A & Wykonawca B & Wykonawca B \\
\hline Korelacja & SOCMI & Petrol (Refinery) & SOCMI & Petrol (Refinery) \\
\hline Średni błąd [\%] & 28,55 & $-51,52$ & 43,99 & $-77,82$ \\
\hline
\end{tabular}

\section{Wyniki według metody z opływem powietrzem}

W przypadku pomiaru wielkości emisji za pomocą urządzenia Hi Flow Sampler stwierdzono występowanie wartości odstających, które mogły być spowodowane błędami stanowiska w przypadku kołnierza na zwężce. W tablicy 4 zostało pokazane, dla jakich elementów obaj wykonawcy uzyskali zgodność z wartościami odniesienia w granicach 35\%.

Tablica 4. Występowanie zgodności z wartościami odniesienia w przypadku pomiaru urządzeniem Hi Flow Sampler

\begin{tabular}{|c|c|c|}
\hline Element Wykonawca & A & B \\
\hline Kołnierz na zwężce & - & - \\
\hline Kołnierz na szpulce & + & + \\
\hline Otwarta rurka & $+/-$ & + \\
\hline Połączenie gwintowane & $+/-$ & + \\
\hline Zawór MAPEGAZ & $+/-$ & + \\
\hline Zawór SRI & + & + \\
\hline
\end{tabular}

- brak zgodności, + zgodność, +/- wartości odstające w kilku punktach

Tablica 5. Błąd średni pomiaru i odchylenie standardowe

\begin{tabular}{|l|c|c|}
\hline Błąd średni, $e_{a v}[\%]$ & Wykonawca A & Wykonawca B \\
$e_{a v}=\frac{\sum_{i=1}^{n} \frac{100 \cdot\left(x_{i}-x_{r e f i}\right)}{x_{r e f i}}}{n}$ & 32,25 & 3,46 \\
\hline $\begin{array}{l}\text { Odchylenie standardowe, } s_{r}[\%] \\
s_{r}=\sqrt{\frac{\sum_{i=1}^{n}\left(x_{i}-x_{a v}\right)^{2}}{n(n-1)}}\end{array}$ & 16,53 & 30,58 \\
\hline
\end{tabular}

W tablicy 5 przedstawiono obliczone błędy średnie wyników pomiarów otrzymanych przez wykonawców oraz wyznaczone odchylenia standardowe. Także w przypadku pomiarów tą metodą wykonawcy nie znali wartości odniesienia.

Z obliczeń wyeliminowano wartości odstające, w związku z czym odchylenia standardowe mogą być niższe niż w przypadku pomiarów wykonywanych $\mathrm{w}$ terenie.

Na rysunku 3 zaprezentowano wyniki pomiaru emisji metodą z opływem powietrzem otrzymane przez obu wykonawców.

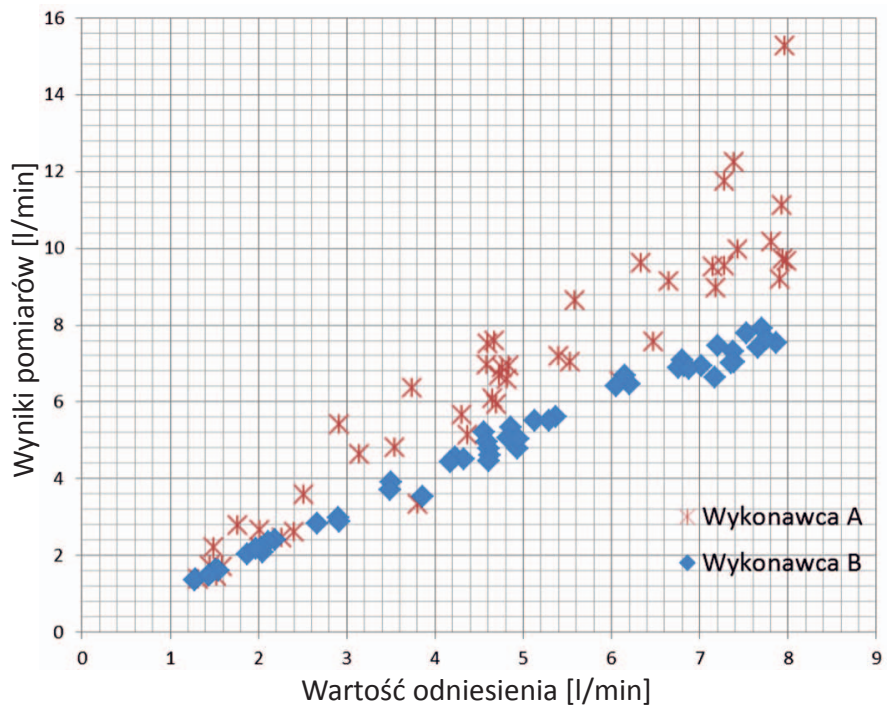

Rys. 3. Wyniki otrzymane przez wykonawcę A i wykonawcę B (bez wyników odstających i wyników dla kołnierza na zwężce)

\section{Przyczyny różnic w wynikach pomiarów}

Podstawowym problemem okazał się pomiar wielkości emisji na kołnierzu na zwężce. Wyniki pomiarów były znacznie 


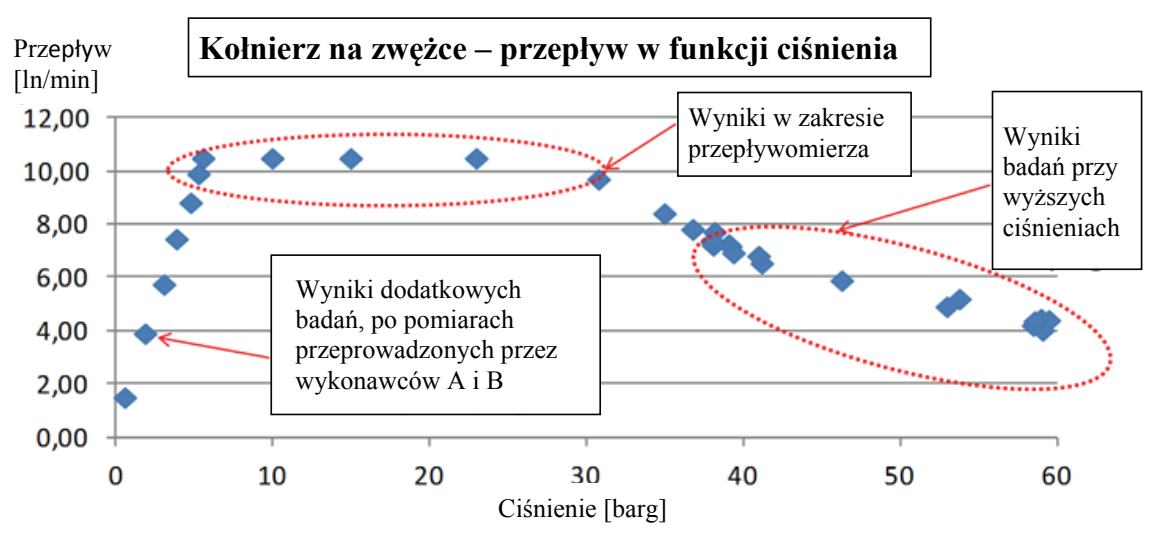

Rys. 4. Wyniki badań kołnierza na zwężce - strumień objętości w funkcji ciśnienia

wyższe niż zarejestrowane przez przepływomierz. Przyczyny różnic sprawdzał Crigen - wykonano dodatkowe testy w całym zakresie ciśnień do 60 bar.

Jak widać, przy ciśnieniach do około 5 bar zależność przepływu od ciśnienia jest zgodna z oczekiwaniem. Przy większym ciśnieniu, aż do 30 bar, przepływ przekracza zakres pomiarowy przepływomierza i stąd widoczny brak zależności przepływu od ciśnienia. W przypadku ciśnień powyżej 30 bar obserwowane jest zmniejszenie przepływu wraz ze wzrostem ciśnienia. Producent (Bronkhorst High-Tech B.V.) termicznego przepływomierza masowego stwierdził, że otrzymane wyniki są standardowe dla tego typu urządzenia, którego zakres pomiarowy wynosi 10 1/min. Rezultaty uzyskane przez obu wykonawców były znacznie wyższe niż wskazywane przez przepływomierz, ale w tym przypadku okazało się to błędem metody pomiaru wartości odniesienia.

Inne obserwowane różnice pomiędzy wynikami obu wykonawców mogły wynikać z różnego podejścia do instrukcji producenta, która przez wykonawcę B była ściśle przestrzegana, podczas gdy wykonawca A poddawał ją modyfikacji polegającej np. na szczelnym owijaniu badanego elementu.

\section{Podsumowanie}

Oszacowanie wielkości emisji gazu ziemnego z systemu przesyłowego jest trudne, ponieważ może być ona rozproszona na długości całego łańcucha dostaw gazu, mającego bardzo wiele różnych elementów i procedur eksploatacyjnych.

Metoda opisana w normie EN 15446 umożliwia oszacowanie wielkości emisji z różnych źródeł przez pomiar stężenia w ppm, które może być przeliczone na $\mathrm{kg} / \mathrm{h}$ za pomocą korelacji. Gdy stężenie przekracza górny zakres pomiarowy urządzenia, przyjmowana jest stała wartość, niezależna od rzeczywistej wielkości. Należy zauważyć, że dolna granica wykrywania jest bardzo dobra -10 ppm lub nawet mniej.

Metoda z opływem powietrzem umożliwia wyznaczenie przepływu gazu z nieszczelności przez próbkowanie przy większych nieszczelnościach. Dolna granica wykrywania wynosi około 1,0 1/min

Pomimo że wykonawcy deklarowali, iż mają doświadczenie w wykonywaniu pomiarów obiema metodami, stosowali - w przypadku metody według [2] - urządzenia pomiarowe o różnym zakresie pomiarowym, a w przypadku metody z opływem powietrzem odmiennie realizowali procedurę pomiarową, co mogło być przyczyną otrzymania różnych wyników.

Zastosowanie korelacji SOCMI dało wartości wyższe o $29 \%$ do $44 \%$ od wartości odniesienia, podczas gdy warto- ści z użyciem korelacji EPA Petroleum Industry były niższe o 52\% do 78\%. Różnica w wynikach może być spowodowana albo stosowaniem przez wykonawców różnych urządzeń, albo brakiem korelacji odpowiedniej dla przemysłu gazowniczego.

W przypadku wykorzystania urządzenia Hi Flow Sampler wyniki były bliższe wartościom odniesienia - błąd średni wyniósł około $32 \%$ dla wykonawcy A i około 3,5\% dla wykonawcy B. Wykonawca B ściślej przestrzegał wytycznych producenta urządzenia, co może wskazywać na celowość normalizacji tej metody.

Partnerzy projektu doszli do wniosku, że wskazane byłoby kontynuowanie projektu, którego celem jest opracowanie metody pomiaru emisji gazu dla małych (poniżej 1,5 1/min) uchodzeń oraz korelacji przeznaczonej dla przemysłu gazowniczego. Przewidujemy, że projekt będzie obejmował m.in.:

- stworzenie bazy z doświadczeniami innych firm,

- opracowanie propozycji metod pomiarowych,

- projekt prototypu urządzenia do pomiaru emisji,

- przeprowadzenie badań i wypracowanie procedury pomiarowej,

- opracowanie korelacji odpowiedniej dla gazownictwa, która mogłaby zostać znormalizowana. 
Prosimy cytować jako: Nafta-Gaz 2016, nr 8, s. 660-665, DOI: 10.18668/NG.2016.08.11

Artykuł nadesłano do Redakcji 1.02.2016 r. Zatwierdzono do druku 27.04.2016 r.

Artykuł powstał na podstawie referatu zaprezentowanego na Konferencji Naukowo-Technicznej FORGAZ 2016 „Techniki i technologie dla gazownictwa - pomiary, badania, eksploatacja”, zorganizowanej przez INiG - PIB w dniach 13-15 stycznia 2016 r. w Muszynie.

\section{Literatura}

[1] Instruction 0055-9017 Operation \& Maintenance of Hi Flow Sampler, Bacharach, USA, 2010.

[2] Inventory of natural gas emissions measurement and detection methods. Raport Eni Power \& Gas Division, E.ON Ruhrgas AG, FLUXYS, GAZ-SYSTEM S.A., GDF SUEZ, NV Nederlandese Gasunie, Snam Rete Gas, 2010.

[3] Method 21 - VOC Leaks, United States Environmental Protection Agency, https://www3.epa.gov/ttnemc01/method21. html (dostęp: 20.04.2016).

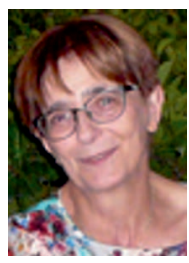

Dr inż. Eliza DYAKOWSKA

Ekspert

Dział Nowych Technologii

Operator Gazociągów Przesyłowych

GAZ-SYSTEM S.A.

ul. Mszczonowska 4, 02-337 Warszawa

E-mail:eliza.dyakowska@gaz-system.pl

\section{Akty prawne i normatywne}

[4] European Standard EN 15446 Fugitive and diffuse emissions of common concern to industry sectors - Measurement of fugitive emission of vapours generating from equipment and piping leaks, January 2008.

\section{OFERTA}

\section{ZAKŁAD OCZYSZCZANIA I UZDATNIANIA PALIW GAZOWYCH}

Zakres działania:

- odsiarczanie gazu ziemnego oraz gazów kwaśnych (metoda IGNiG-Chelate);

- metody głębokiego odsiarczania i uzdatniania gazu ziemnego do zasilania ogniw paliwowych;

- badania nad technologią ogniw paliwowych zasilanych gazem ziemnym;

- $\quad$ nieinwazyjne metody kontroli szczelności łłoczni gazu, w tym metody laserowe zdalnej detekcji metanu, lokalizacja wycieków, precyzyjne pomiary wielkości emisji metanu z tłoczni gazu;

- metody korelacyjne wyznaczania właściwości energetycznych paliw gazowych;

- $\quad$ oznaczanie składu i właściwości fizykochemicznych paliw gazowych;

- $\quad$ nowe metody wykorzystania gazu, w tym m.in.: w klimatyzacji, chłodnictwie, do napędu pojazdów oraz w układach kogeneracyjnych;

- badania biogazów, prognozowanie uzysku biogazu.

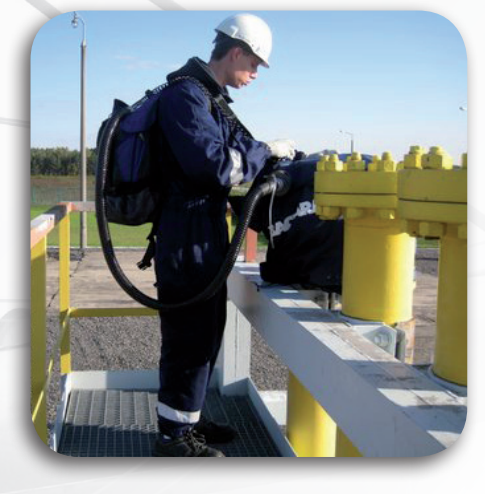

